\title{
Design of FACTS Device For The Improvement of Power System Stability using Mathematical Matching Controller
}

\author{
S. Sowjanya, Prof. J. Srinivasarao \\ ${ }^{I}$ (Electrical and Electronics Department, QIS College of Engieering and Technology, India)
}

\begin{abstract}
The power system installed with a FACTS device demonstrates the application of the model in analyzing the damping effect of the FACTS device stabilizer to improve power system oscillation stability. In case of single-machine infinite bus power systems to be studied and an example power system is presented which show the negative damping influence of STATCOM DC voltage regulator on power system oscillation and the effectiveness of STATCOM stabilizer superimposed on a STATCOM AC voltage regulator to counter attack the negative damping effect. The principle and working of STATCOM, how the STATCOM control the reactive power flow in transmission line can be explained. Philips-Heffrons model of a power system installed with a static synchronous compensator (STATCOM) and demonstrates the application of the model in analyzing the damping effect of the STATCOM and designing a STATCOM stabilizer to improve power system oscillation stability.
\end{abstract}

Keywords: Flexible AC transmission systems, Static Synchronous Compensator, Damping effect, Genetic and Evolutionary algorithm, Power System Stability

\section{INTRODUCTION}

Modern electric power system is a complex network of synchronous generators, transmission lines and loads. The characteristics of the system vary with changes in load and generation schedules. Electric utilities first grew as isolated systems, and then gradually neighboring utilities began to join forming highly interconnected systems. This enabled the utilities to draw on each other's generation reserves during the time of need. The overall reliability has improved through interconnection but disturbances in such systems propagate through, leading to system instability and possible black-outs. Systems which have long transmission distances between the load centers and generating stations. may exhibit poorly damped or even negatively damped oscillations. If the magnitude of disturbance is large, such as a three phase fault, major line or load switching, the system could even become transiently unstable. A good power system should possess the ability to regain its normal operating condition after a disturbance. Since ability to supply uninterrupted electricity determines the quality of electric power supplied to the load, stability is regarded as one of the important topics of power system research.

FACTS controllers can improve the security of a power system by enhancing its steady-state and transient stability or by damping the sub-synchronous resonance oscillations. An important FACTS device is the Static synchronous compensator (STATCOM), which can control all three principle parameters (voltage, impedance and phase angle) and used for dynamic compensation of power system to provide voltage support and stability improvement. STATCOM is a flexible ac transmission system device, which is connected as a shunt to the network, for generating or absorbing reactive power. A number of studies have been performed about the dynamic behavior of STATCOM and its application to improve the transient performance of power systems.

The Static Synchronous Compensator(STATCOM) is a new generation Flexible ACTransmission System (FACTS) device with promising applications. It is based on the principle that a voltagesource converter (VSC) generates a controllable AC voltage behind a transformer leakage reactance so that the voltagedifference across the reactance produces active and reactivepower exchange between the STATCOM and transmissionnetwork. The primary function of STATCOM in a powersystem is to increase transmission capability, with a giventransmission network. Since STATCOM (without EnergyStorage) cannot generate or absorb real power, the power transmission capability of the system is affected indirectlyby voltage control. This line voltage control is implementedby an AC voltage controller in the STATCOM byregulating the amount of reactive power injected into or absorbed from the power system.

The static synchronous compensator (STATCOM) is based on the principle that a voltage-source inverter generates a controllable AC voltage source behind a transformer-leakage reactance[18,19].The AC voltage difference across the leakage reactance produces reactive power exchange between the STATCOM and the power system such that the AC voltage at the bus bar can be regulated so as to improve the voltage profile of the power system, which is the primary duty of the STATCOM. However, if necessary, a secondary damping function can be added into the STATCOM for enhancing power system oscillation stability. If the STATCOM 
converter is based on the PWM, a third control function is neededto control thr DC voltage across the capacitor in the STATCOM. Therefore, a STATCOM may be multiple functional controller, which is one of the important features of new generation FACTS controllers. The investigation of the ffect of AC and DC voltage regulator on power system oscillation damping and to design a STATCOM damping controller to enhance system oscillation stability. The conventional proportional-integral (PI) controller is utilized for STATCOM controlling to damp the electromechanical oscillations of power systems. The parameters of PI controller should be chosen to make the PI controller to perform well over a wide range of operating conditions.

\section{SINGLE-MACHINE INFINITE-BUS POWER SYSTEM INSTALLED WITH A STATCOM}

A Single Machine Infinite Bus (SMIB) system with STATCOM located at the midpoint of the transmission line (Fig.1) is considered. IEEE type STIA model of static excitation system has been considered.

The main objective is to design a controller for STATCOM for a single-machine infinite-bus (SMIB) power system. The STATCOM is modeled as a reactive current source. A static synchronous compensator (STATCOM) is a shunt connected FACTS device, which is capable of enhancing the power system damping by exchanging reactive power with the system. STATCOM for improvement power system transient stability.

In a single-machine infinite-bus power system installed with a STATCOM which consists of a step-down transformer (SDT) with a leakage reactance ' $\mathrm{X}$ ' a three phase GTO-based voltage source converter (VSC) and a DC capacitor. The VSC generates a controllable AC-volt age source behind the leakage reactance. The voltage difference between the STATCOM-bus AC voltage $V L$ and $V O$ produces active and reactive power exchange between the STATCOM and the power system, which can be controlled by adjusting the magnitude $V o$ and the phase. Where, for the PWM inverter, $\mathrm{c}=m k$ and $\boldsymbol{k}$ is the ratio between AC and DC voltage, depending on the inverter structure; $\boldsymbol{m}$ is the modulation ratio defined by the PWM; and the phase is defined by the PWM. The STATCOM model is the enhanced dynamic model recommended for stability study of power systems. Although this model may not be valid for transient (internal short-circuits, for example) phenomena and unsymmetrical conditions, it is good enough for the study of power system oscillation stability.

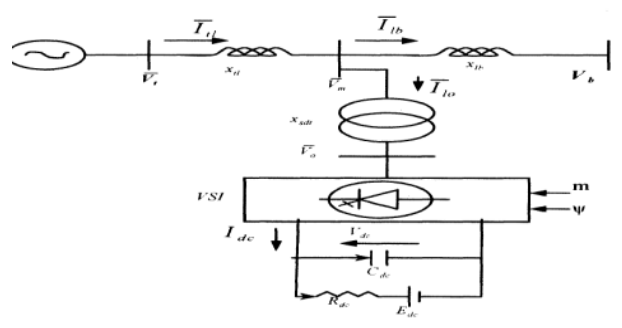

Fig.1.Circuit Diagram of SMIB system with STATCOM:

\subsection{Damping enhancement through statcom:}

A STATCOM plays an important role in reactive power provision and voltage support because of its attractive steady state performance and operating characteristics. A number of studies have been performed about the dynamic behavior of STATCOM and its application to improve the transient performance of power systems. However, proper control strategies are necessary in order to achieve full utilization of STATCOM. Some of the controllers designed are simple lag-lead controllers, conventional PI controllers, controllers designed by the phase compensation method, the linear quadratic regulators, pole assignment. Fuzzy controllers for STATCOM. Selection of input signal is one of the important items in designing a controller. Some of the auxiliary input signals used for STATCOM controllers are delivered active power, the STATCOM bus voltage, computed internal voltage, and synthesized remote phasor, driving point reactance seen from STATCOM location. Most of the controllers' designed for STATCOM are based on linearized model of the power system and hence are suitable for particular operating points. Changes in operation in the system occur because of the load changes as well as for unpredictable disturbances. A controller designed for operation at certain operating condition may not perform satisfactorily at other operating points. A controller that is designed to operate over a set of perturbed operating points can circumvent the mentioned problem of uncertainty of power system operation. Such a controller is known as robust controller. Thus designing a robust controller which will operate efficiently over a range of operating conditions is highly desirable. 


\section{EQUATIONS FOR ANALYSIS}

The dynamic model of the system with STATCOM/BESS is given below:

$$
\begin{aligned}
& \dot{\delta}=\omega_{0} \Delta \omega \\
& \Delta \dot{\omega}=\frac{1}{M}\left(P_{m}-P_{e}-D \Delta \omega\right) \\
& \dot{E}_{q}^{\prime}=\frac{1}{T_{d o}^{-}}\left(E_{f d}-E_{q}\right) \\
& \dot{E}_{f d}=\frac{1}{T_{a}}\left(K_{a}\left(V_{t r e f}-V_{t}+u\right)-E_{f d}\right) \\
& \dot{V}_{d c}=\frac{m}{C_{d c}}\left(I_{l o d} \operatorname{Cos} \psi+I_{l o q} \operatorname{Sin} \psi\right)-\frac{V_{d c}-E_{d c}}{R_{d c}}
\end{aligned}
$$

Where

$$
\begin{aligned}
& P_{e}=E_{q}^{\prime} i_{t q}+\left(x_{q}-x_{d}^{\prime}\right) i_{t d} i_{t q} \\
& E_{q}=E_{q}^{\prime}+\left(x_{d}-x_{d}^{\prime}\right) i_{t d} \\
& V_{t}=\sqrt{\left(E_{q}^{\prime}-x_{d}^{\prime} i_{t d}\right)^{2}+\left(x_{q} i_{t q}\right)^{2}} \\
& e_{d}=x_{q} i_{t q} \quad e_{d}=E_{q}^{\prime}-x_{d}^{\prime} i_{t d} \\
& i_{t d}=\frac{\left(x_{l b}+x_{s d t}\right) E_{q}^{\prime}-x_{l b} m V_{d c} \sin \psi-x_{s d t} V_{b} \cos \delta}{Z_{d}} \\
& i_{t q}=\frac{x_{l b} m V_{d c} \cos \psi+x_{s d t} V_{b} \sin \delta}{Z_{d}} \\
& I_{l o d}=\frac{E_{q}^{\prime}-\left(x_{d}^{\prime}+x_{t l}\right) i_{t d}-m V_{d c} \operatorname{Sin} \psi}{x_{s d t}} \\
& I_{l o q}=\frac{m V_{d c} \operatorname{Cos} \psi-\left(x_{q}+x_{t l}\right) i_{t q}}{x_{s d r}}
\end{aligned}
$$

Where,

$$
\begin{aligned}
& Z_{d}=x_{l b} x_{s d t}+x_{l b} x_{t l}+x_{t l} x_{s d t}+\left(x_{s d t}+x_{l b}\right) x_{d}^{\prime} \\
& Z_{q}=x_{l b} x_{s d t}+x_{l b} x_{t l}+x_{t l} x_{s d t}+\left(x_{s d t}+x_{l b}\right) x_{q} \\
& u \text { is the stabilizing signal from Power System Stabilizer } \\
& \text { (PSS). The dynamic model is a nonlinear model. }
\end{aligned}
$$

\subsection{Linear dynamic model:}

The linear dynamic model in state space form given below is obtained by linearising the nonlinear model around a nominal operating condition.

$$
\begin{aligned}
& \dot{X}=A X+B 1 U 1+B 2 U 2 \\
& X=\left[\begin{array}{llll}
\Delta \delta & \Delta \omega & \Delta E_{q}^{I} & \Delta E_{f d} \Delta V_{d c}
\end{array}\right]^{T} \\
& \mathrm{U} 1=\left[\begin{array}{ll}
\Delta m & \Delta \psi
\end{array}\right]^{T} \\
& \mathrm{U} 2=\left[\Delta P_{m} \Delta V_{\text {Ref }}\right]^{T}
\end{aligned}
$$

In this model K1-K9, $K_{P d}, K_{v d}, K_{q d}$ are scalar constants, while the constant $K_{P u}, K_{q u}, K_{q u}, K_{d u}$ are row vectors defined as follows:

$$
K_{P u}=\left[K_{P m} K_{P \psi}\right]
$$




$$
\begin{aligned}
& K_{q u}=\left[K_{q m} K_{q \psi}\right] \\
& K_{v u}=\left[K_{v m} K_{v \psi}\right] \\
& K_{d u}=\left[K_{d m} K_{d \psi}\right]
\end{aligned}
$$

Control vector u is column vector, $\mathrm{U} 1=\left[\begin{array}{ll}\Delta m & \Delta \psi\end{array}\right]^{T}$

All the above constants of the model are function of operating condition and system parameters.

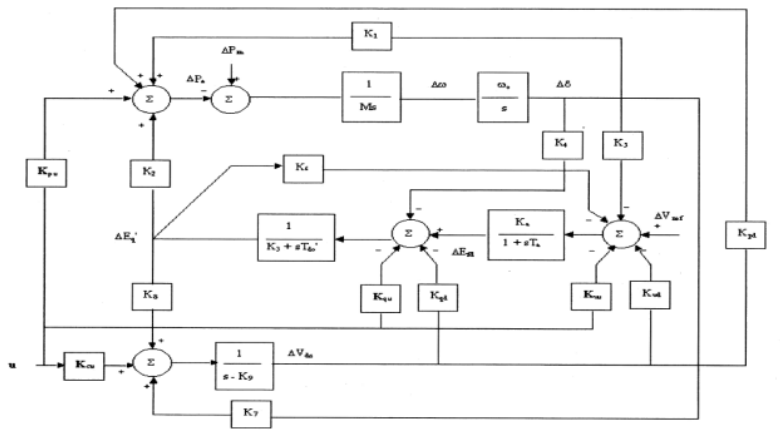

Fig.1. block

diagram for a system installed with statcom

The transfer function response is shown below:

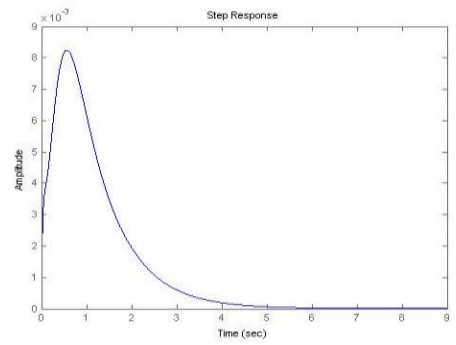

Dynamic Response

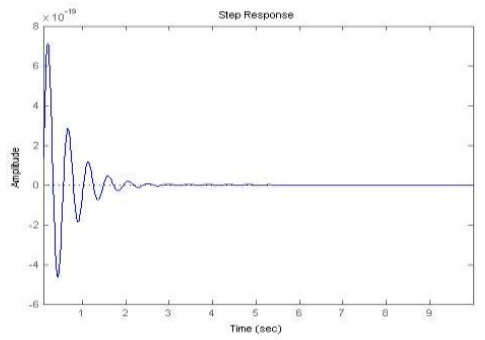

In the below plot, we can observe that the operating points for different values are obtained in the negative axis. Hence we know that the operating points are placed in the negative axis gives that the system is unstable. Hence to make the system stable, we detect the most unstable plant to stabilize it.

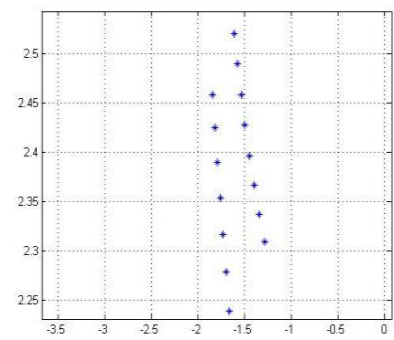

Plot without STATCOM 
In the below plot, we can observe that the operating points in the positive axis. Hence the system is stable. It is possible with the FACTS device controller i.e., STATCOM. Hence the system is stable. By using the model matching technique, the response of the lower order controller is matched with the model controller.

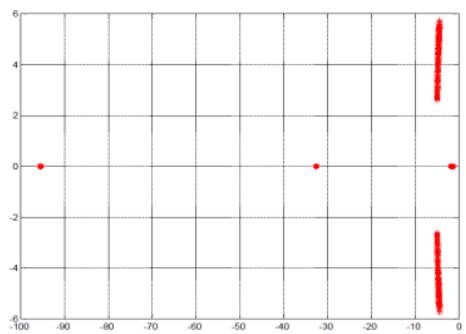

Plot with STATCOM

\section{CONCLUSION}

The significant contribution of work is mathematical modeling of the SMIB with STATCOM for different operating points.Checked the stability of the plant without any controller.Location of poles for different operating points and finding most unstable plant.Developed MODEL controller to the most unstable plant and stabilized the plant.Reduced the order of the MODEL controller by order reduction techniques. Matched the response of the lower order controller with model controller by model matching techniques. Applied GA technique for optimization of error between the model controller and low order controller.By using optimization technique the performance measure ' $\mathrm{J}$ ' is Measured.

\section{REFERENCES:}

[1] Design of statcom controllers with energy storage system using gea M L Kothari, J C Patra.

[2] H.F. Wang, "Phillips-Heffron model of power systems installed with STATCOM and applications," IEE Proc.-Gener. Transm. Distrib.. Vol. 146, No. 5, September 1999.

[3] GYUGYI, L., HINGORANI, N.G., NANNERY, P.R., and TAI, T.: 'Advanced static Var compensator using gate turn-off thynstors for utility applications'. CIGRE, Pans, 1990, pp. 23-203

[4] GYUGYI, L.: 'Reactive power generation and control by thyristor Circuits', ZEEE Trans., 1979, IA-15, (5), pp, 521-532 IEE ProcGener. Transm. Distrib., Vol. 146, No. 5, September 1999

[5] SCHAUDER, C., and MEHTA, H.: 'Vector analysis and control of advanced static VAR compensator', ZEE Proc. C, 1993, 140, (4), pp.

[6] SCHAUDER,C., GERNHARDT,M., STACEY,E., CEASE, T.W., and EDRIS, A.: 'Development of a 2 100 MVAR static condenser for voltage control of transmission systems', IEEE Truns. Pwr. Deliv., 1995, 10, (3), pp. 14861496

[7] EKANAYAKE, J.B., JENKINS, N., and COOPER, C.B.: 'Expenmental investigation of an advanced static Var compensator', IEE Proc. Gener. Trunsm. Distrib., 1995, 142, (2), pp. 202-210

[8] SAAD-SAOUD, Z., LISBOA, M.L., EKANAYAKE, J.B.,JENKINS, N., and STRBAC, G.: 'Application of STATCOMs to wmd farms', IEE Proc. Gener. Trunsm. Distrib., 1998, 145, (5), pp. 51 1-516

[9] TRAINER, D.R., TENNAKOON, S.B., and MORRISON, R.E.: Analysis of GTO-based static VAR compensators', IEE Proc. Gener.Trunsm. Distrib., 1994, 141, (6), pp. 293-302

[10] AINSWORTH, J.D., DAVIES, M., FITZ, P.J., OWEN, K.E., and TRAINER, D.R.: 'Static Var compensator (STATCOM) based on single-phase chain circuit converters', IEE Proc. Gener. Trunsm. Distrib., 1998, 145, (4), pp. 381-386

[11] MORI, S., MATSUNO, K., TAKEDA, M., and SETO, M.: 'Development of a large static Var generator using selfcommutated inverters for improving power system stability', IEEE Truns. Pwr. Syst., 1993,

[12] WANG, H.F., and SWIFT, F.J.: 'An unified model for the analysis of FACTS devices in damping power system oscillations. Part I: singlemachine infinite-bus power systems', IEEE Truns. Pwr. Deliv., 1997,

[13] WANG, H.F., SWIFT, F.J., and LI, M.: 'An unified model for the analysis of FACTS devices in damping power system oscillations. Part

[14] Multi-machne power systems', IEEE Truns. Pwr. Deliv., 1998, 13,(4), pp. 1355-1362

[15] HEFFRON, W.G., and PHILLIPS, R.A.: 'Effect of a modem amplidyne voltage regulator on under excited operation of large turbine generator', AIEE Trans., 1952,71

[16] WANG, H.F.: 'Selection of operating conditions for the co-ordinated setting of robust fm-parameter stabilisers', IEE Proc. Gener. Trunsm.Distrib., 1998, 145, (2), pp. 11 1-1 18

[17] WANG, H.F.: 'The phase compensation method to design FACTSbased stabilizer. Part I: single-machine infinite-bus power systems',Adv. Model. Anal., C, 1998, 1, (52) 299-30658, (I), pp. 371-37812, (2), pp. 941-926

[18] WANG, H.F.: 'The phase compensation method to design FACTSbasedstabilizer. Part I1 multi-machine power systems', Adv. Model.Anal., C, 1998, 1, (52)

[19] Modelling of power electronics equipment (FACTS) in load flow and stability programs'. CIGRE

[20] U, Y.N.: 'Electric power system dynamics' (Academic Press, 1983) 